\title{
POBLACIONES DE Aspergillus EN SEMILLAS DE MAIZ Y SOJA DE IMPORTACION ARGENTINA: ENFASIS EN LA SECCION FLAVI
}

\author{
(Aspergillus population in maize and soja seed imported from Argentina: \\ Emphasis on section Flavi)
}

\author{
*Constanza Sepúlveda O. \& **Eduardo Piontelli L \\ *Pontificia Universidad Católica de Valparaíso, \\ Instituto de Biología, Avenida Brasil 2950, Valpartaíso, Chile. \\ **Universidad de Valparaíso, Escuela de Medicina, Cátedra de Micología. \\ Casilla 92 V, Val.paraíso Chile.
}

Palabras clave: Aspergillus, sección Flavi soja, maíz, Argentina Key words: Aspergillus, section Flavi, soya, maize, Argentine

\section{RESUMEN}

Durante un período de 5 meses se realizaron muestreos seriados en granos de maíz y soja de procedencia Argentina para estudiar la presencia de especies del género Aspergillus (en especial los de la sección Flavi). Para ambos tipos de granos se tomaron 10 muestras mensuales obtenidas de un puerto terrestre (Los Andes, Chile), desde submuestras transportadas en bolsas plásticas y proporcionadas por personal de control sanitario. Los granos se sembraron por duplicado en placas de Petri, utilizando 2 medios: agar malta sal (AMS) y agar agua sal (AAS). Todos los Aspergillus, fueron transferidos posteriormente en agar malta (AM) y agar czapek con extracto de levadura (CYA), para su determinación morfológica final, análisis poblacional, frecuencia de presencia en el tiempo y la posible producción de aflatoxinas (sección Flavi) en medio de cultivo específico. En maíz y soja y en ambos medios, se detectó un total de 1669 colonias del género Aspergillus (1193 en AMS y 476 en AAS), representando 18 taxa, (17 en maíz y 15 en soja), éstos fueron en órden decreciente: Aspergillus flavus, Eurotium amstelodami, E. rubrum, A.ellipticus, A.niger, A.candidus, A.ochraceus, A.terreus, A.versicolor, A.glaucus, A. tamarii, A.clavatus, A.ostianus, A. sydowii, A. fumigatus, A.parasiticus, A.wentii y A. sclerotiorum. Los 5 primeros taxa representaron el 85,7\% de la presencia total. En general en maíz y soja la especie dominante fue A. flavus, mientras $\boldsymbol{E}$. amsteIodami y E. rubrum fueron más frecuentes en soja. Los valores más altos de presencia en maíz fueron en julio y en soja en noviembre. A.flavus presentó alta dominancia en ambos granos, seguida con baja frecuencia de A.tamarii y A. parasiticus. Para un análisis morfológico poblacional se seleccionaron al azar 50 cepas de A. flavus de todos los subtratos y muestras. En AM y CYA, se observaron cabezas radiadas a columnares laxas mayoritariamente, aproximadamente la mitad de las cepas presentaron cabezas biseriadas y los conidios de 7 y 14 días (medidos con un procesador de imágenes), no tuvieron mayores variaciones en sus diámetros, pero levemente en sus rugosidades. El 86\% de las cepas formaron esclerocios, siendo todos de tipo L. Mediante visualización de un halo azul fluorescente bajo luz UV en agar coco, un $44 \%$ de las cepas de A.flavus, produjeron aflatoxinas. Las cepas de A.parasiticus fueron negativas. A pesar que no se consideraron otras comunidades productoras de micotoxinas presentes en estos granos, la alta ocurrencia de $\boldsymbol{F}$. verticillioides en maíz, debe considerarse por sus efectos nocivos en la dieta animal y en salud pública.

\section{ABSTRACT}

Serial sampling of maize and soja grains imported from Argentina were carried out for five months in order to study the occurrence of Aspergillus species (mainly those of Flavi section). For both kind of grains, ten monthly samples collected from a terrestrial port (Los Andes, Chile) were taken from subsamples transferred in plastic bags and supplied by sanitary control personnel. Grains were cultured in duplicate on Petri dishes by using two media: malt salt agar (AMS)and salt water agar (AAS). All Aspergillus detected were lately transferred in malt agar (AM) and czapek agar added with yeast extract (CYA) to determine its ultimate morphological character, 
population analysis, frequency of occurrence in time and possible production of aflotoxins in Flavi section in a particular medium of culture.In maize and soja and in both media,1669 colonies of the genus Aspergillus (1193 in AMS and 476 in AAS) was detected, representing 18 taxa, (17 in maize and 15 in soja), which in decreasing order were:Aspergillus flavus, Eurotium amstelodami, E.rubrum, A.ellipticus, A.niger, A.candidus, A.ochraceus, A.terreus, A.versicolor, A.glaucus, A.tamarii, A.clavatus, A.ostianus, A.sydowii, Afumigatus, A.parasiticus, A.wentii and A.sclerotium. The first five taxa represented $85.7 \%$ of the overall total. In general, the dominant species was A.flavus in maize and soja, whereas E.amstelodami and E.rubrum were most frequent in soja. Highest values of occurrence in maize were in july and in november, in soja. A.flavus exhibited high dominance in both grains followed by a low frequency of A.tamarii and A.parasiticus. Fifty strains of A.flavus were randomly selected from every substrate and sample in order to carry out a population analysis. In AM and CYA, radiated heads to columnar laxa were mostly observed, about half strains exhibited biserial heads whereas 7-14day conidia (measured with an image processer) did not reveal any further change in diameter yet they showed some changes in rugosity. Eighty six per cent of strains formed sclerotia, all of type L. By means of the visualization of a fluorescent blue halo under an UV light in coconut agar, 44\% of A.flavus strains produced aflatoxins. Strains of A.parasiticus were negative. Although other communities producing mycotoxins which are present in these grains were not considered, the high occurrence of F.verticillioides in maize samples should be studied because of its harmful effects in animal diet and in public health.

\section{INTRODUCCION}

Las semillas de maíz y soja ya sea en el campo como en almacenaje, poseen una microbiota particular asociada a bacterias, hongos e insectos que pueden producir daños al mismo grano como o la planta. El ataque fúngico puede empezar en los tejidos sanos o dañados por agentes biológicos o factores ambientales (Wicklow, 1995; Woloshuk et al., 1997). En los campos de cultivos, estas semillas están en contacto directo con comunidades de hongos presentes en el suelo o la vegetación circundante, tales como varios integrantes de los géneros: Fusarium, Penicillium, Alternaria, Paecilomyces, Scopulariopsis etc., pero en especial por especies de Aspergillus y Penicillium, que bajo condiciones ambientales apropiadas (temperatura y humedad) y su gran capacidad xerofílica ( $\mathrm{a}_{\mathrm{w}}$ bajo 0,90$)$, pueden ser los primeros colonizadores del grano en el almacenaje, causando biodeterioro (Moss, 1991; Wicklow, 1995; Horn \& Dorner, 1998; Samson et al., 2000).Dentro de las actividades biológicas de importancia en el almacenamiento, se destaca la producción de micotoxinas, estimándose que cada año, el $25 \%$ de las cosechas mundiales se ven afectadas por la colonización fúngica (Osweiler, 1992; Devegowda et al., 1998).

El maíz es uno de los substratos más comunes en la presencia de micotoxinas, especialmente cuando se cultiva en zonas tropicales o cálidas, donde los integrantes del género Aspergillus y Fusarium encuentran las condiciones de temperatura y humedad óptimas para su desarrollo (Picco \& Piontelli, 2005).

El género Aspergillus, es de gran relevancia en la producción de estos metabolitos, en especial algunas especies de la sección Flavi (A.flavus, A.parasiticus y A.nomius) que producen aflatoxinas B1, B2, G1, G2, con potenciales mutagénicos y carcinogénicos en humanos y animales (Kurtzman et al., 1987; Klich \& Pitt, 1988). Sin embargo, dentro de la sección, A.tamarii, A.oryzae y A.sojae no producen aflatoxinas debido a la variabilidad genética en sus poblaciones (Bayman \& Cotty, 1993; Cotty et al., 1994; Wicklow, 1995; Horn \& Dorner, 1998). Entre otros colonizadores de los granos de maíz en las zonas cálidas y húmedas, F.verticillioides, es un conocido fitopatógeno capaz de producir fusarinas y fumonisinas (B1 y otras) con similares capacidades mutagénicas y carcinogénicas que las aflatoxinas (González et al., 1997; Horn \& Dorner, 1998).

La presencia de micotoxinas en los alimentos, conlleva a riesgos agudos o crónicos en salud pública, con repercusiones nacionales e internacionales en el ámbito del control sanitario y por consiguiente en la comercialización de éstos granos (Van Egmond, 1989).

Las especies de Aspergillus de la sección Flavi, se han estudiado en maíz en muchas partes del mundo (Wicklow, 1991; Zumo \& Scott, 1990; Weidenbörner et al.,1996). Argentina, aporta abundante información al respecto, especialmente en la provincia de Santa Fe, que produce casi el $30 \%$ de la cosecha nacional (Farnochi et al., 1988; Nepote et al., 1988, 1994, 1997; Resnik, 1988a, 1988b; Chulze et al., 1989 ; Resnik et al., 1996; Etcheverry et al., 1999; Picco et al., 1999; Nesci \& Etcheverry, 2002), pero también cultiva otros productos agrícolas, como maní, sorgo, algodón, trigo, etc., en climas considerados cálidos, húmedos y propicios para el desarrollo fúngico y la producción de micotoxinas (Varsavsky et al., 1985; Dalcero et al. 1997; Magnoli et al., 1998; Barros et al., 2003; Pildain et al., 2004).

Los objetivos principales de esta investigación fueron: determinar y caracterizar morfológicamente en tres períodos estacionales, las poblaciones del género Aspergillus en semillas de maíz y soja de importación, comparar las posibles variaciones morfofisiológicas en 
cultivo de los integrantes de la sección Flavi y su producción de aflatoxinas en un medio indicador.

\section{MATERIALES Y METODOS}

a) Obtención de la muestra. Todas las muestras de semillas de maíz y soja fueron de procedencia argentina, las cuales llegaron a granel al puerto terrestre en Los Andes, Chile, donde las autoridades sanitarias controlan la posible entrada de malezas e insectos mediante muestreos seriados que se transportan a los laboratorios de análisis para su posterior procesamiento hasta su incineración en el tiempo. De las muestras iniciales, se obtuvieron submuestras aleatorias de aproximadamente unos $250 \mathrm{~g}$ de ambos granos, los cuales se trasladaron al laboratorio en bolsas plásticas estériles para el análisis de la presencia fúngica. Se obtuvieron muestras de 5 meses distintos, representando 3 estaciones (julio y agosto del 2004 (invierno), septiembre y noviembre del 2004 (inicio y término de primavera) y enero del 2005 (verano). Se procesaron en cada uno de los meses citados 10 muestras de maíz y 10 de soja. Con un total de 50 muestras de cada tipo de grano. A pesar que todas las muestras tenían una rotulación numérica de acceso interno, no fue posible obtener datos de la región de procedencia de estos granos.

\section{b) Métodos del cultivo y siembra de los granos Medios de cultivos utilizados.}

1.- Agar malta sal (AMS). Con un contenido de $\mathrm{NaCl}$ de $50 \mathrm{~g} / \mathrm{L}$ La sal se agrega con varios fines: Evitar la germinación de los granos, aumentar la presión osmótica al bajar la actividad de agua $\left(a_{w}\right)$ en el cultivo y facilitar el crecimiento de hongos xerofílicos, en especial las especies de Aspergillus que son el objetivo de nuestro estudio. Este medio, debido a sus nutrientes solubles, estimula el desarrollo de muchos hongos, en especial los de crecimiento rápido. Además se agregaron 0,0025 mg/L de Diclorán, para reducir el tamaño de todas las colonias fúngicas asociadas, en especial los Mucorales. 2.- Agar agua sal (AAS). Con un contenido de $\mathrm{NaCl}$ de 50 g/L y 0,0025 mg/L de Diclorán. Este medio solo representa una cámara húmeda y el único substrato presente es el maíz o la soja, donde el crecimiento fúngico se aprecia directamente sobre los granos dispuestos en la superficie del agar o alrededor de ellos. Todos los hongos reducen su tiempo de crecimiento y tamaño de las colonias frente a un substrato no soluble.

Ambos medios no tuvieron un fin netamente comparativo, sino más bien, se emplearon para obtener la mayor diversidad de integrantes del género Aspergillus, bajo las diferentes condiciones de los substratos.

\section{Técnica de siembra de los granos}

Diez granos de cada muestra (maíz y soja) tomados al azar desde varias profundidades de las bolsas, con pinza plana esterilizada a la llama sucesivamente, se sembraron por duplicado directamente sobre la superficie del agar en placas de Petri de $10 \mathrm{~cm}$ de diámetro de la siguiente forma:

Se colocaron 8 granos sobre la superficie de ambos medios, cerca del borde interno de la placa a una distancia de $1 \mathrm{~cm}$ aproximadamente entre ellos y los restantes (2) se colocaron en el centro de la placa.

Las placas se incubaron a $27^{\circ} \mathrm{C}$ por $10-20$ días. Los Aspergillus detectados creciendo sobre los granos o en el agar subyacente a estos, fueron contabilizados para determinar su frecuencia relativa, determinándose las especies en un primer intento presuntivo in situ ya sea por sus características macro y/o microscópicas, con preparaciones en lactofenol con azul de algodón.

La Frecuencia de aislamientos de cada especie de Aspergillus en cada uno de los medios en duplicado, fue calculada de acuerdo al total de colonias detectadas en cada grano, en todas las muestras de los meses analizados.

En cada muestra y en cada medio de cultivo y sus duplicados, se sumaron las presencias de los Aspergillus spp. en los 20 granos por muestra, calculándose como valor final el promedio ( 0 a 10 ) de la presencia en ambas placas. Cuando las sumas de los duplicados arrojaron números impares, el promedio se aproximó al número entero superior.

Posteriormente, para aislar las cepas al estado puro, se sembró al azar un representante de cada especie de Aspergillus en tubos de agar AM inclinado en cada una de las muestras mensuales, las que se incubaron por 7 días a $27^{\circ} \mathrm{C}$. Estas cepas se guardaron para la posterior identificación en medios especiales.

\section{c) Determinación de las especies de Aspergillus en medios especiales}

Desde los aislamientos al estado puro y mediante arrastre con asa estéril sobre la superficie de las colonias, se preparó una abundante suspensión de conidios en 2cc de agua destilada estéril, para posteriormente sembrarse nuevamente en placas de Petri de $10 \mathrm{~cm}$, en AM y CYA. La siembra de cada cepa de Aspergillus, se realizó desde la suspensión con una micropipeta colocando tres gotas de $0,07 \mu \mathrm{l}$ en 3 puntos centrales en la superficie del agar de cada medio, simulando un triángulo, para obtener 3 colonias equidistantes. Se incubaron las placas por $14-20$ días o más a $25^{\circ} \mathrm{C}$, para apreciar la presencia de todos los elementos morfológicos específicos y tardíos como esclerocios y cleistotecios. 


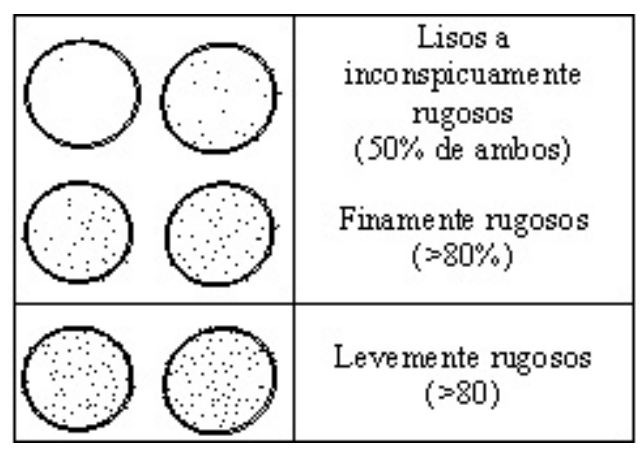

Figura 1. Tipos de rugosidades de las paredes de los conidios de cepas de A. flavus en AM, a los 7 y 14 días.

A los 7 días, se analizaron las colonias en AM y CYA midiéndose sus diámetros (en mm), además se observaron los colores del anverso y reverso de las colonias, la presencia de pigmentos solubles; el aspecto de la colonia bajo lupa, tales como tipos de cabezas conidiales, presencia o ausencia del exudado y color.

Con microscopía óptica en AM y aumento de 1000x, se observaron y midieron las rugosidades, colores y formas de los conidióforos, vesículas, métulas fiálides y conidios.

\section{d) Aspergillus de la sección Flavi.}

Los integrantes de esta sección fueron identificados de la misma manera que en el punto c. En más de la mitad de la cepas obtenidas de $\boldsymbol{A}$. flavus, 50 se seleccionaron al azar (28 de maíz y 22 de soja) para efectuar mediciones finas de sus conidios en su eje mayor a los 7 y 14 días en AM, mediante un procesador de imágenes KS-100 conectado a una cámara Canon digital y a un microscopio Zeiss. En las mediciones se consideraron sólo 2 decimales. Para diferenciar el tipo de rugosidad observado en los diferentes tiempos de cultivo, se establecieron 3 categorías, indicadas en la Figura 1. Considerando al mismo tiempo las principales características macro y microscópicas para apreciar posibles variaciones intraespecíficas. La presencia y medida de esclerocios y/o cleistotecios se efectuó entre los 14 y 20 días.

Las monografías utilizadas para la descripción de los Aspergillus fueron: Raper y Fennell (1965), AlMusallam (1980), Klich \& Pitt (1988), Kozakiewicz (1989) y Klich (2002a).

\section{e) Análisis Estadístico}

Para la comparación de la distribución de las diferentes especies de Aspergillus contabilizadas en maíz y soja, se utilizó el índice de distribución de Shannon (H') en cada mes de estudio.

\section{f) Presencia de Aflatoxinas}

Para determinar la presencia de aflatoxinas en las poblaciones de A. flavus y A. parasiticus, se utilizó el medio rápido de detección Agar Coco (AC). En éste se sembraron las cepas por 5 días a $25^{\circ} \mathrm{C}$, para ser observadas bajo luz Ultra Violeta (UV a $365 \mathrm{~nm}$ ), la cual en presencia de la toxina presenta un halo fluorescente azul alrededor de la colonia (Davis et al., 1987).

\section{RESULTADOS}

\section{a) Presencia y distribución de las especies de Aspergillus en maíz y soja,}

En los granos de maíz y soja se detectó la presencia de un total de 1669 colonias de Aspergillus en ambos medios (AMS y AAS), que representaron 18 taxa: Aspergillus candidus, A.clavatus, A.ellipticus, A.flavus, A.fumigatus, A.glaucus, A.niger, A.ochraceus, A.ostianus, A.parasiticus, A.sclerotiorum, A.sydowii, A.tamarii, A.terreus, A.versicolor, A.wentii, Eurotium amstelodami y E. rubrum (Tabla 1, Figura 2. D, E, F, G, H). La mayoría de los aislamientos (70\%), correspondieron al subgénero Circumdati de Aspergillus y a 5 de sus secciones: Candidi (5,63\%), Circumdati (4.01\%), Flavi (45,90\%), Nigri (14,14\%) y Wentii $(0,12 \%)$, siguiendo en importancia el subgénero Aspergillus con un $23,01 \%$. El resto incluyó el subgénero Nidulantes $(6,59 \%)$, Clavati $(0,36 \%)$ y Fumigati $(0,24 \%)$.

De los 18 taxa, los más importantes para ambos granos y que representaron el $85,7 \%$ del total de presencia, destacaron: A. flavus (n=752), E. amsteIodami ( $\mathrm{n}=185)$, E. rubrum ( $\mathrm{n}=163)$, A.ellipticus $(\mathrm{n}=137)$, A.niger $(\mathrm{n}=99)$ y A. candidus $(\mathrm{n}=94)$ (Tabla 1). Estos tuvieron un comportamiento distinto en ambos granos en los 5 meses de estudio, a excepción de $\boldsymbol{A}$. ellipticus y A. candidus (Figura 2. A, B, C, D,E, F ).

En maíz, A. flavus tuvo su pick más alto en julio, mientras en agosto, septiembre y noviembre, el número de cepas encontradas fue similar, bajando solo en enero. En soja, la curva es ascendente encontrándose el pick más alto en noviembre (Tabla 1, Figura 2. A).

E. amstelodami y E. rubrum se detectaron con mayor frecuencia en soja (Tabla 1) y $\boldsymbol{E}$. amstelodami tuvo sus mayores pick en julio y noviembre, mientras que en maíz, la mayor frecuencia se presentó en agosto (Tabla 1, Figura 2 B ). E. rubrum se detectó fuertemente en agosto para la soja, mientras que en maíz lo hizo en julio y especialmente en enero (Tabla 1, Figura $2 \mathrm{C}$ ).

A. ellipticus, presentó una curva de comportamiento similar para ambos granos en los meses de estudio, encontrándose 2 pick, en agosto y noviembre (Tabla 1, Figura 2 D). 


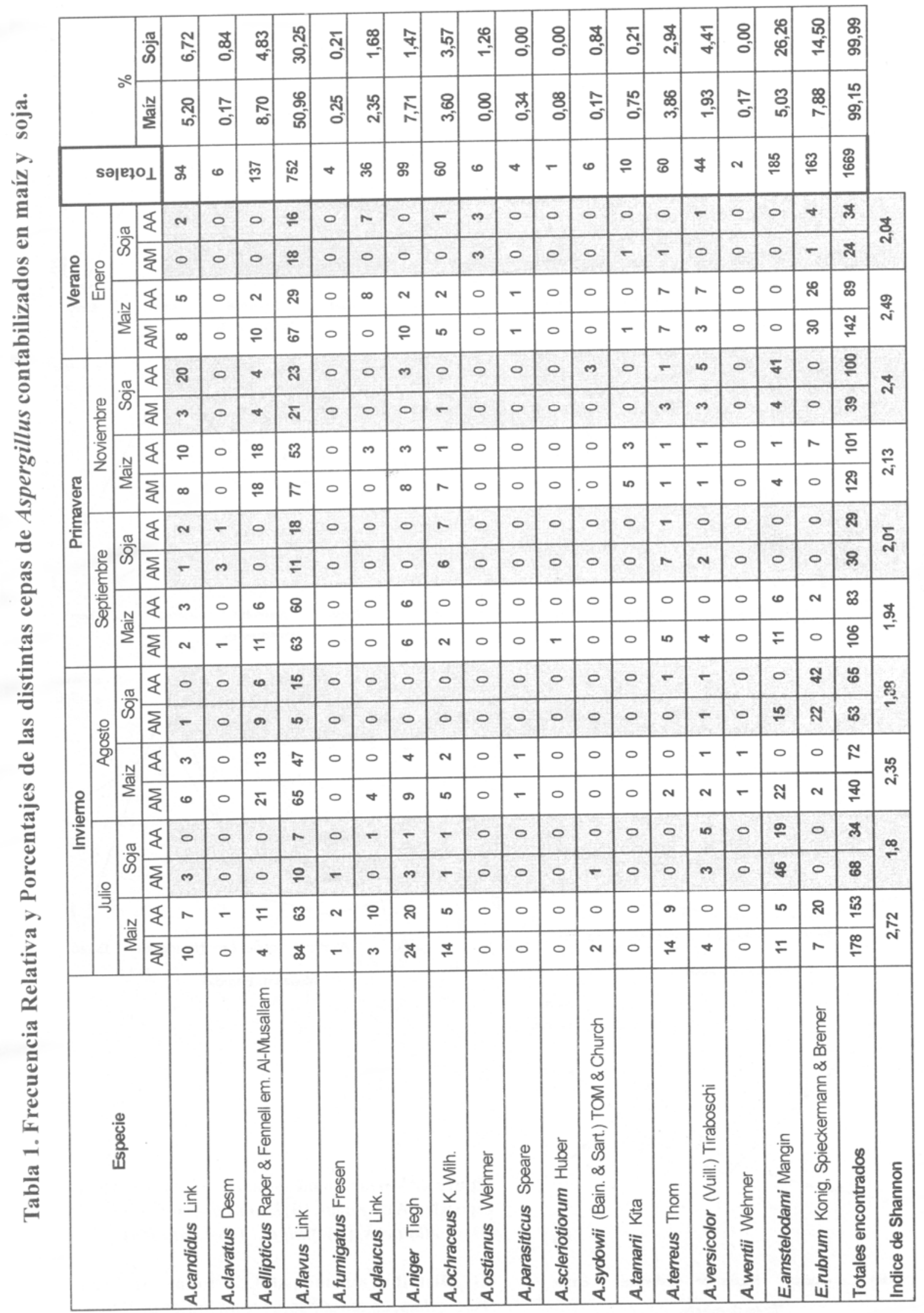



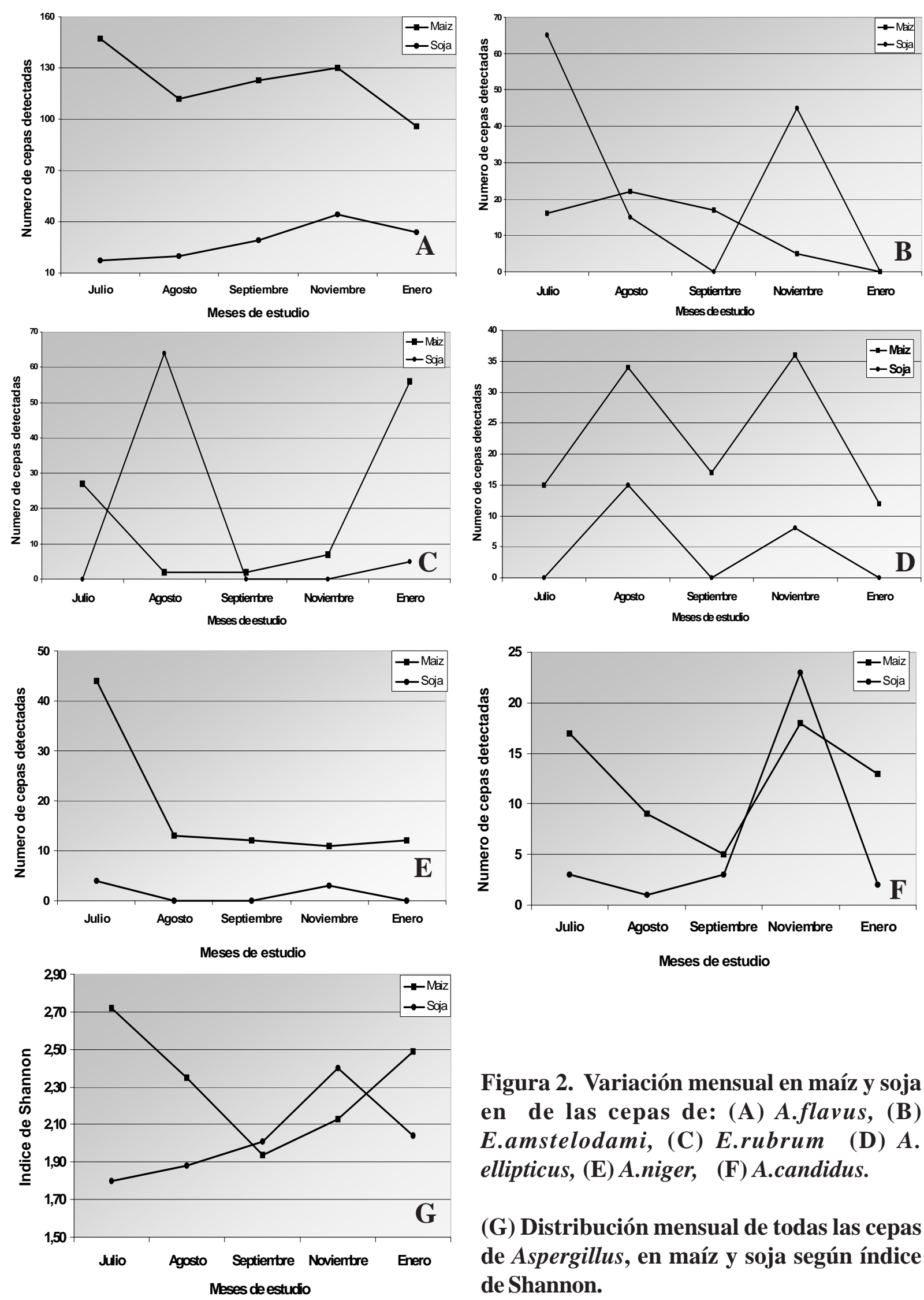

Figura 2. Variación mensual en maíz y soja en de las cepas de: (A) A.flavus, (B) E.amstelodami, (C) E.rubrum (D) A. ellipticus, (E) A.niger, (F) A.candidus.

(G) Distribución mensual de todas las cepas de Aspergillus, en maíz y soja según índice de Shannon. 
A. niger tuvo su mayor pick en julio, en el resto de los meses la cantidad de cepas encontradas fue similar entre sí; en soja solo se encontraron unos pocos aislamientos en julio y noviembre (Tabla 1, Figura 2 E).

A. candidus tuvo un comportamiento bastante similar en ambos granos, las mayores diferencias se encontraron en julio y enero (Tabla 1, Figura 2 F).

El análisis de la distribución mensual de las especies de Aspergillus (Según Shannon), presenta diferencias para los dos granos (Tabla 1, Fig. 2 .G). En maíz, el valor más alto se encontró en julio ( $\left.\mathrm{H}^{\prime}=2,72\right)$ y en septiembre el más bajo $\left(H^{\prime}=1,94\right)$. Por su parte, la soja presentó el valor más alto en noviembre $\left(\mathrm{H}^{\prime}=2,4\right)$, y el más bajo en julio (H’ =1,8) (Tabla 1, Figura 2. G).

\section{b) Maíz}

Se detectó la presencia de un total de 1193 colonias de Aspergillus en ambos medios, 695 en AMS y 498 en AAS, representando 17 taxa: A. candidus, A.clavatus*, A.ellipticus*, A.flavus*, A.fumigatus, A.glaucus, A.niger, A.ochraceus*, A.parasiticus*, A.sclerotiorum*, A.sydowii, A.tamarii*, A.terreus*, A.versicolor*, A.wentii, E. amstelodami* y E.rubrum* (Tabla. 1)(* En Figuras 6-7).

En AMS las 5 especies con mayor frecuencia fueron: A.flavus (51,21\%), A.ellipticus (9,20\%), A.niger (8,20\%), E.amstelodami (6,91\%) y E.rubrum (5,61\%), mientras que en AAS, las 5 especies de mayor frecuencia fueron: A.flavus (50,60\%), E.rubrum (11,04\%), A.ellipticus (10.04\%), A.niger (7,03\%) y A.candidus (5,62\%) (Tabla 1).

En julio y en ambos medio se observó el mayor número de presencia de especies de Aspergillus $(\mathrm{n}=331)$ y los 4 meses restante tuvieron presencias inferiores, pero similares entre sí (Tabla 1, Figura 3).

En todos los meses de estudio, el taxa dominante en ambos medios fue A. flavus, siendo siempre mayor en AMS (Tabla 1).

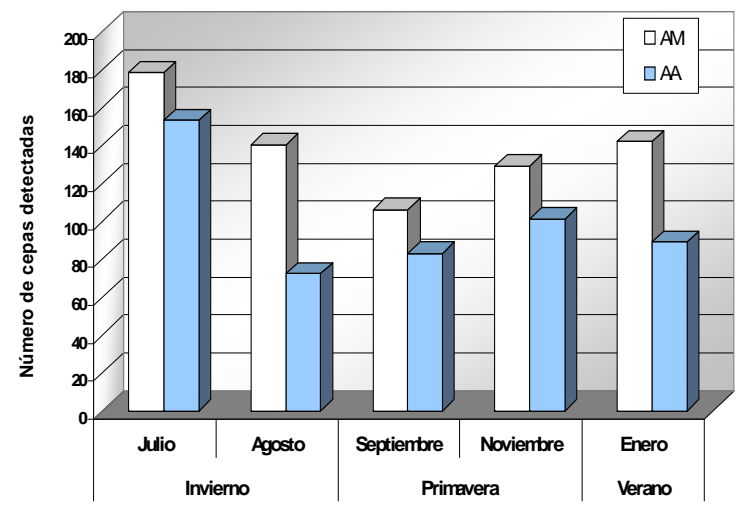

Figura 3. Variación mensual en maíz de todas las cepas de Aspergillus en todos los medios.
Cabe destacar que todos los granos de maíz no sólo presentaron especies de Aspergillus, sino un variado número de taxa, donde Fusarium (F.verticillioides) siempre presentó la mayor ocurrencia, seguido en menor medida por especies de Penicillium, Rhizopus y Absidia entre otras.

c) Soja:

Se detectó la presencia de un total de 476 colonias de Aspergillus en ambos medios, 214 en AMS y 262 en AAS, representando 15 taxa: A.candidus, A.clavatus, A.ellipticus, A.flavus, A.fumigatus, A.glaucus, A.niger, A.ochraceus, A.ostianus, A.sydowii, A.tamarii, A.terreus, A.versicolor, E. amstelodami y E.rubrum (Tabla 1).

En AMS las 5 especies con mayor frecuencia fueron: A.flavus y E.amstelodami, ambas con 30.37\%, E.rubrum 10.75\%, A.ellipticus 6,07\% y A.terreus 5,14\%, mientras que en ASS las de mayor frecuencia fueron: A.flavus (30.15\%), E.amstelodami (22.9\%), E.rubrum 17.56\%, A.candidus (9,14\%) y A.versicolor (4,58\%).

A.ostianus*, sólo se aisló en soja, mientras A.parasiticus, A.sclerotiorum y A.wentii no se presentaron en este substrato (Tabla 1) (*Figura 6, 3).

En noviembre y en ambos medio se observó el mayor número de presencia de Aspergillus ( $\mathrm{n}=139$ ), seguidos por agosto y julio $(\mathrm{n}=118 \mathrm{y} 102)$. Septiembre $\mathrm{y}$ enero fueron similares entre sí (Tabla 1, Figura 4).

Aspergillus flavus, sigue siendo dominante en

ambos medios (30,25\%), pero no en todos los meses.

La soja a diferencia del maíz, presentó una gran carga bacteriana, que disminuyó la presencia de los integrantes del género Aspergillus, como otros taxa fúngicos. Fusarium no estuvo presente y sólo se apreciaron pocas colonias de Penicillium y Rhizopus principalmente.

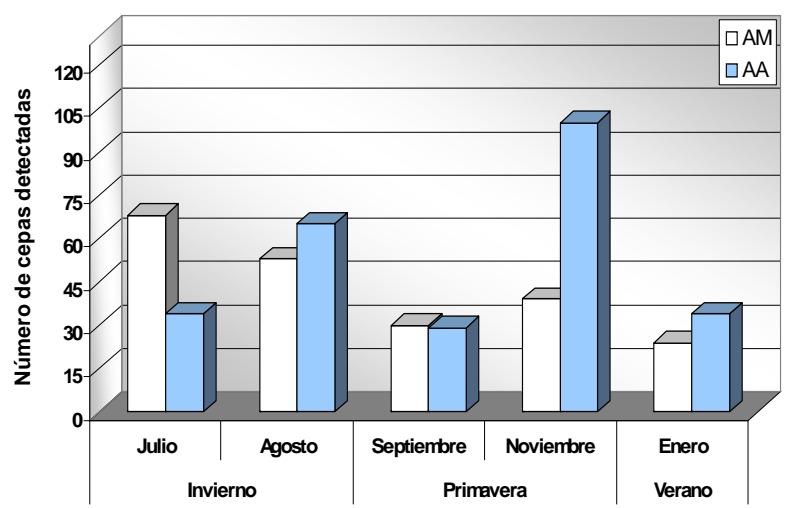

Figura 4. Variacion mensual en soja de todas las especies de Aspergillus en ambos medios. 
Tabla 2. Principales características de las cepas de A. flavus en CYA, AM y Agar Coco, aisladas de maíz y soja.

\begin{tabular}{|c|c|c|c|c|c|}
\hline $\begin{array}{l}\text { Aspecto } \\
\text { cabezas } \\
\text { CYA }\end{array}$ & $\begin{array}{c}\text { Aspecto } \\
\text { cabezas } \\
\text { AM }\end{array}$ & $\begin{array}{c}\text { Rugosidad } \\
\text { conidios } 7 \text { días }\end{array}$ & $\begin{array}{c}\text { Rugosidad } \\
\text { conidios } 14 \text { días }\end{array}$ & $\begin{array}{c}\text { Mono y } \\
\text { Biseriado }\end{array}$ & $\begin{array}{c}\text { Halo azul } \\
\text { fluorescente } \\
\text { en } \\
\text { Agar coco }\end{array}$ \\
\hline $\begin{array}{l}\text { Radiadas } \\
\text { laxas } \\
33 \text { cepas }\end{array}$ & $\begin{array}{l}\text { Radiadas } \\
\text { laxas } \\
11 \text { cepas }\end{array}$ & $\begin{array}{c}\text { Lisos a } \\
\text { inconspicuamente } \\
\text { rugosos } \\
\mathbf{3 8} \text { cepas } \\
\end{array}$ & $\begin{array}{c}\text { Lisos a } \\
\text { inconspicuamente } \\
\text { rugosos } \\
\mathbf{3 0} \text { cepas } \\
\end{array}$ & $\begin{array}{l}>50 \% \\
\text { monoseriados } \\
27 \text { cepas }\end{array}$ & $\begin{array}{l}\text { Sin halo } \\
28 \text { cepas }\end{array}$ \\
\hline $\begin{array}{l}\text { Radiadas } \\
\text { laxas a } \\
\text { columnares } \\
17 \text { cepas }\end{array}$ & $\begin{array}{l}\text { Radiadas } \\
\text { laxas a } \\
\text { columnares } \\
\mathbf{3 9} \text { cepas }\end{array}$ & $\begin{array}{c}\text { Finamente } \\
\text { rugosos } \\
6 \text { cepas }\end{array}$ & $\begin{array}{l}\text { Finamente } \\
\text { rugosos } \\
6 \text { cepas }\end{array}$ & $\begin{array}{l}>50 \% \\
\text { biseriados } \\
23 \text { cepas }\end{array}$ & $\begin{array}{l}\text { Halo tenue } \\
13 \text { cepas }\end{array}$ \\
\hline & & $\begin{array}{l}\text { Levemente } \\
\text { rugosos } \\
6 \text { cepas }\end{array}$ & $\begin{array}{l}\text { Levemente } \\
\text { rugosos } \\
\mathbf{1 4} \text { cepas }\end{array}$ & & $\begin{array}{c}\text { Halo intenso } \\
9 \text { cepas }\end{array}$ \\
\hline
\end{tabular}

e) Aspectos morfofisiológicos de los Aspergillus de la sección Flavi en maíz y soja

La alta dominancia de A.flavus descrita anteriormente en ambos substratos, fue seguida en baja proporción por A.tamarii (0,75\% en maíz y 0,21\% en soja) y A.parasiticus (0,34\% sólo en maíz) (Tabla 1).

1.- Macromorfología. Todas las cepas de A.flavus tuvieron un crecimiento rápido en CYA a los 7 días (46 $79 \mathrm{~mm}$ y una media de 60,66 mm) y en AM en el mismo tiempo (47 - 70,3 mm y un promedio de $62 \mathrm{~mm}$ ). Más del $81 \%$ de las cepas tuvieron medias entre los 55 y $70 \mathrm{~mm}$. Visualmente, A.flavus presentó siempre colores más claros que A.parasiticus y A.tamarii, con una tonalidad verde amarillenta que bajo un mismo tipo de iluminación, no marcó diferencias en CYA y MEA con las cartas de colores. Esta situación fue claramente comparable debido a la profusa esporulación de todos los aislamientos y no se modificó a pesar de la alta presencia de esclerocios. Los 10 aislamientos de A.tamarii, presentes solo en noviembre y enero principalmente en maíz , fueron estables en sus tonalidades de café con un componente rojizo, no presentaron esclerocios y crecieron todas a $37^{\circ} \mathrm{C}$ (descartándose A.pseudotamarii), por lo que todas se consideraron pertenecientes al tipo A . A.parasiticus se presentó en 4 ocasiones en ambos medios, en invierno y verano. Sólo la cepa aislada en invierno y en AM, produjo pocos esclerocios con una media de 756 x $718 \mu \mathrm{m}$.

2.- Micromorfología. Las características microscópicas principales en AM (solo se estudian en este medio) fueron: cabezas conidiales de aspecto radiadas laxas o radiadas laxas a francamente columnares. Las vesículas midieron entre 25,6 y 51,5 $\mu \mathrm{m}$, con un promedio de 38,5 $\mu \mathrm{m}$. Aproximadamente la mitad de las cepas presentaron métulas y fiálides (Tabla 2).

Las rugosidades de los conidios a los 7 y 14 días, no presentaron marcadas diferencias. La mayoría de ellos, en ambos tiempos, tuvieron paredes con superficies lisas a finamente rugosas. Sólo se apreció a los 14 días, un aumento dentro de la categoría «Levemente rugosos».

Las medidas promedio de los diámetros o del eje más largo de los conidios, mediante el procesador de imágenes, a los 7 y 14 días, no presentó mayor variación y fueron de 3,97 y 3,96 $\mu$ m respectivamente. De los 6226 conidios medidos, el tamaño menor fue de 2,51 $\mu \mathrm{m}$ y el mayor de $6 \mu \mathrm{m}$ (datos no mostrados). Veinte cepas bajaron sus diámetros a los 14 días, 8 se mantuvieron iguales y 22 subieron.

En la figura 5 se muestra la dispersión de los diámetros de los conidios a los 7 y 14 días. Sólo algunas

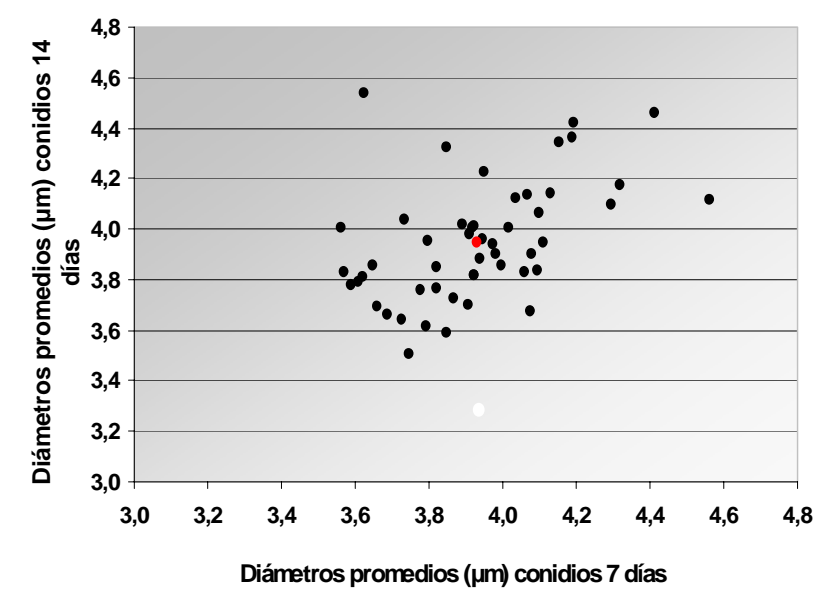

Figura 5. Relación entre 7 y 14 días de incubación para los diámetros mayores de los conidios de A. flavus en agar malta 

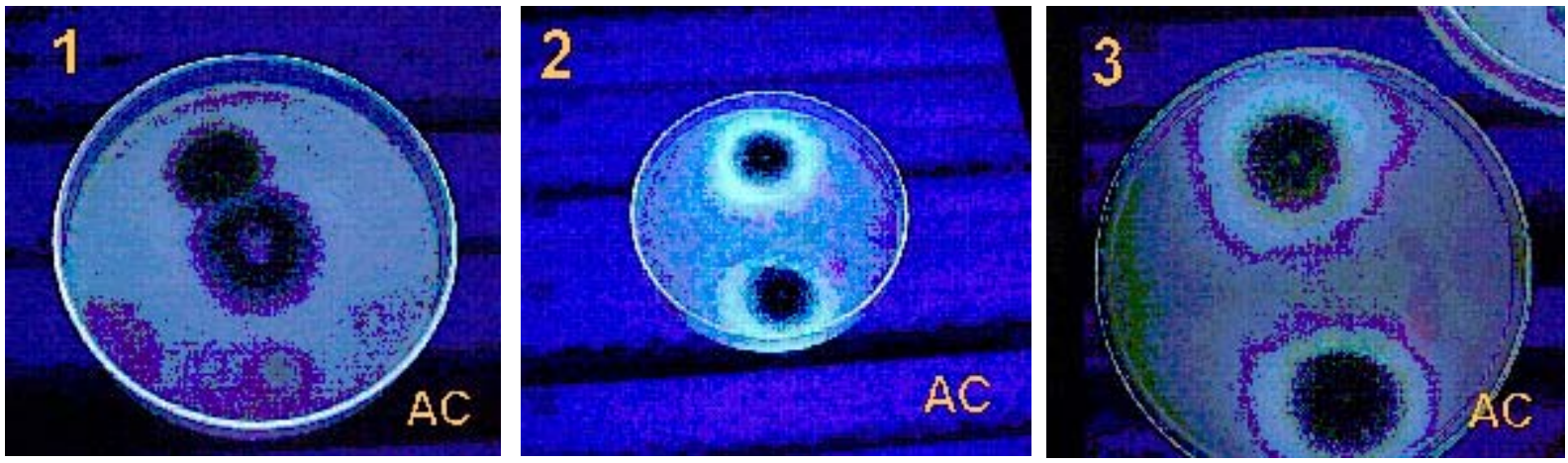

Figura 6.- Producción de halo azul fluorescente de las cepas de A. flavus en Agar Coco a los 5 días de incubación. 1.- Sin producción de halo, 2.- Halo fuertemente fluorescente, 3. Halo con ténue fluorescencia

cepas se alejan del promedio general, apreciándose que pocas aumentan o disminuyen sus diámetros en el tiempo, variando principalmente entre los 3.6 y $4.2 \mu \mathrm{m}$. El 86\% de las cepas presentó formación de esclerocios (en CYA a los 14 días), todas correspondientes al tipo L (Promedio: 785.8 x $682.2 \mu \mathrm{m}$ ). En AM, el $52 \%$ de las cepas también los presentó (tipo L), aunque las medidas promedios fueron levemente menores que en CYA. (746.0 x $634.2 \mu \mathrm{m})$.

\section{3.- Presencia de Aflatoxinas en las cepas de A.flavus y A.parasiticus en medio de cultivo Agar Coco}

De las 50 cepas analizadas, el $56 \%$ no produjeron halo azul fluorescente bajo luz UV en Agar Coco, a los 5 días de incubación, el 18\% fue fuertemente fluorescente y el 26\% mostró una tenue fluorescencia (Tabla 2, Figura 6 ). Siete de las cepas aisladas en noviembre presentaron producción de halo azul fluorescente, en enero, agosto y septiembre 4 cepas y en julio 3 (datos no mostrados).

Ninguno de los 2 aislamientos de $A$. parasiticus seleccionados presentó halo fluorescente.

\section{DISCUSION}

Nuestro trabajo principalmente de orientación descriptiva, se realizó sólo para estudiar la presencia de las poblaciones del género Aspergillus (en especial la sección Flavi), en granos de maíz y soja de procedencia argentina, sin considerar el lugar de origen o los previos almacenamientos de éstos 2 productos. Considerando que el destino final de estos substratos constituye parte de la dieta animal en nuestros mercados nacionales, estimamos de interés analizar cualitativa y cuantitativamente la presencia de estos organismos que poseen características fisiológicas relevantes, como crecer a una baja actividad de agua y presentar una problemática sanitaria por la producción de variadas micotoxinas
(Chulze et al., 1989; Moss, 1991; Hocking, 1991; Wicklow, 1995; Bayman \& Cotty, 1993; EHSO, 2004 ).

El maíz y la soja, son los mayores productos generados en Argentina y la mitad de éstos, se exportan a mercados externos (Bolsa de Cereales, 1999). La presencia de variados hongos toxicogénicos en estos granos puede ocurrir ya sea durante el ciclo de su desarrollo en el campo (especialmente en el maíz), después de la cosecha y/o en el almacenamiento, alterando la seguridad de estos alimentos en las dietas humanas y animales. Entre estos hongos destacan en nuestra investigación los integrantes del subgénero Circumdati, como A. ochraceus productor de ocratoxina A, junto a otras especies no incluidas en esta sección, A. versicolor productor de sterigmatocistina, un precursor biosintético de aflatoxinas, pero con propiedades carcinogénicas menores que la aflatoxina B (Samson et al., 2000). Sin embargo, en nuestros aislamientos preocupa la alta frecuencia de los integrantes de la sección Flavi (A.flavus y A.parasiticus), los cuales, frente a factores ambientales específicos, pueden producir algunas o todas las aflatoxinas (B1, B2, G1 y G2), potentes metabolitos teratogénicos y carcinogénicos (Klich \& Pitt, 1988; Cotty et al., 1994; Wicklow, 1995; Woloshuk et al., 1997).

Argentina tiene una amplia zona de cultivos de maíz y soja, que presentan distintos tipos de climas (cálidos y húmedos) y suelos que afectan en cierta medida la ecología y distribución de los hongos en general y las especies de Aspergillus en particular. No existe una tendencia general en la distribución de los integrantes de este género según bioma, pero sus distintas secciones parecen tener patrones de distribución diferentes, sin embargo, los climas templados y calurosos entre los 25 y $35^{\circ}$ Latitud (sur o norte) parecen ser más favorables en la ocurrencia de especies del subgénero Circumdati y sus secciones (nuestro estudio), seguramente debido a la temperatura, cuando ésta se mantiene en rangos óptimos para estos hongos 
$\left(23^{\circ}\right.$ a $37^{\circ} \mathrm{C}$ ) durante la mayor parte del año (Christensen \& Tuthill, 1985; Klich, 2002b). Estas latitudes son las que corresponden a las zonas de cultivos de maíz y otros granos en la Argentina (Resnik, 1989).

El conocer la distribución de las especies, toxicogénicas de Aspergillus, permite encarar en los países productores programas de control dirigidos a las probables áreas de riesgo mediante la adecuada rotación de cultivos y el manejo de los rastrojos, fuente primaria de estos hongos (Resnik, 1997).

Los estudios de incidencia llevados a cabo en distintos substratos, en diversos países, muestran que ciertos cultivos son más susceptibles al ataque y colonización de determinados hongos toxicogénicos. A pesar de que este conocimiento no es completo, se sabe que el maíz, maní y algodón son muy susceptibles a la contaminación por hongos productores de aflatoxinas, en contraposición a la soja, trigo y sorgo (Resnik, 1997; Barros et al., 2003).

Las poblaciones naturales de A.flavus que pertenecen a diferentes genotipos, incluyendo cepas con grupos de compatibilidad vegetativa genéticamente aisladas, fueron empleadas para determinar las diferencias de las poblaciones de A.flavus en campos de algodón y maní en USA(Cotty,199; Horn et al., 1996; McAlpin et al., 2002). A.flavus, se reconoce por ser una cepa que se reproduce sólo asexualmente con alguna potencialidad de recombinación por vía asexual entre los individuos morfológicamente similares. En la naturaleza las poblaciones son altamente polimórficas (incluso en la producción de aflatoxinas) y no puede reconocerse si las cepas son recombinantes o completamente clonales (Geiser et al., 1998). La variación en la producción de aflatoxinas en dependencia de las localizaciones geográficas o las divergencias fisiológicas, ha recibido mayor atención en la literatura, por su importancia en salud pública (Niyo, 1990; Bayman \& Cotty, 1993; Egel et al., 1994; Cotty \& Cardwell, 1999). Por la procedencia desconocida de nuestras muestras, no pudimos determinar la localización geográfica de las cepas consideradas toxicogénicas. En Argentina, estudios de la ocurrencia natural de aflatoxinas en diversos granos han demostrado que los niveles de contaminación son variables. En algunos años, éstos han superado lo establecido por las regulaciones internacionales especialmente en el maíz en la zona de Córdoba y sus alrededores (Chulze et al., 1989; Resnick et al., 1996; Etcheverry et al., 1999; Picco et al., 1999; Nesci \& Etcheverry, 2002).

La diversidad también ha sido descrita en su morfología (Raper \&Fennell, 1965; Saito et al., 1986; Bayman \& Cotty, 1993), así como en la virulencia (Cotty, 1989), la producción de conidios, el tamaño y abundancia de los esclerocios (S y L) (Cotty, 1989; Egel et al., 1994) entre otras características.

Los esclerocios juegan un importante rol en la supervivencia y dispersión de A.flavus (Wicklow et al., 1984, 1988). Las cepas L producen más conidios y muestran ser favorables para la colonización, mientras que las cepas $\mathrm{S}$ se orientan más a la formación de estructuras de resistencia para la sobrevivencia y en la producción de mayor cantidad de aflatoxinas (Bayman \& Cotty, 1993).

Todas nuestras cepas de A.flavus que formaron esclerocios, pertenecían al tipo L, las cuales, según la literatura pueden tener una menor capacidad de producir toxinas, entre el 30 y 45 \% (Magnoli et al., 1998). Sólo se han descrito cepas tipo S en Estados Unidos (Cotty, 1989; Doster \& Michailides, 1994a, 1994b), Tailandia (Saito et al., 1986) y Africa (Hesseltine et al., 1970).

En Argentina, se han aislado especies del género Aspergillus en diversos granos, con clara dominancia de A.flavus y con menor frecuencia A.parasiticus, A.nomius, A.candidus, A.fumigatus, A.niger, A.oryzae, A.parvulus, A.tamarii y A.terreus, entre otros (Gonzalez et al., 1988,1997; Magnoli et al., 1998). Siempre la mayor información en maíz (granulados o farináceos compuestos) se refiere a los de la sección Flavi (Reddy, 1987; Nepote et al., 1995,1997; Resnik et al., 1996; González et al., 1997; Etcheverry, 1998; Horn \& Dorner, 1998; Etcheverry et al.,1999; Picco et al., 1999; Nesci \& Etcheverry, 2002; Barros et al., 2003). En nuestro análisis del maíz, A. flavus mantiene esta dominancia sobre las otras especies del género y aunque desconocemos el origen de las muestras, no hay duda que su distribución no depende mayormente de la latitud de las zonas de cultivo, sino de la distribución de esta gramínea y la capacidad competitiva de esta especie en un ecositema favorable.

La soja se mostró como un substrato diferente al maíz en ambos medios, pero mantuvo al igual que este último una alta diversidad de especies del género Aspergillus, a pesar de su menor cantidad numérica. La presencia en la mayoría de las muestras de una alta carga bacteriana de rápido crecimiento (no observada en maíz), pudo limitar en gran medida el desarrollo fúngico. Sin embargo, llama la atención que dos especies con diferentes rangos de actividad mínima de agua como son A. flavus y E. rubrum mantuvieron niveles similares de frecuencia (Samson et al., 2000). La alta incidencia de especies de Eurotium también fue encontrada por Weidenbörner (1997) en soja, usando medios con baja actividad de agua. En una revisión de la micota asociada a las semillas, flores y vainas de la soja en USA se detectaron 14 especies de Aspergillus asociadas a las primeras (Roy et al., 2000). Eurotium, se considera un colonizador primario en granos 

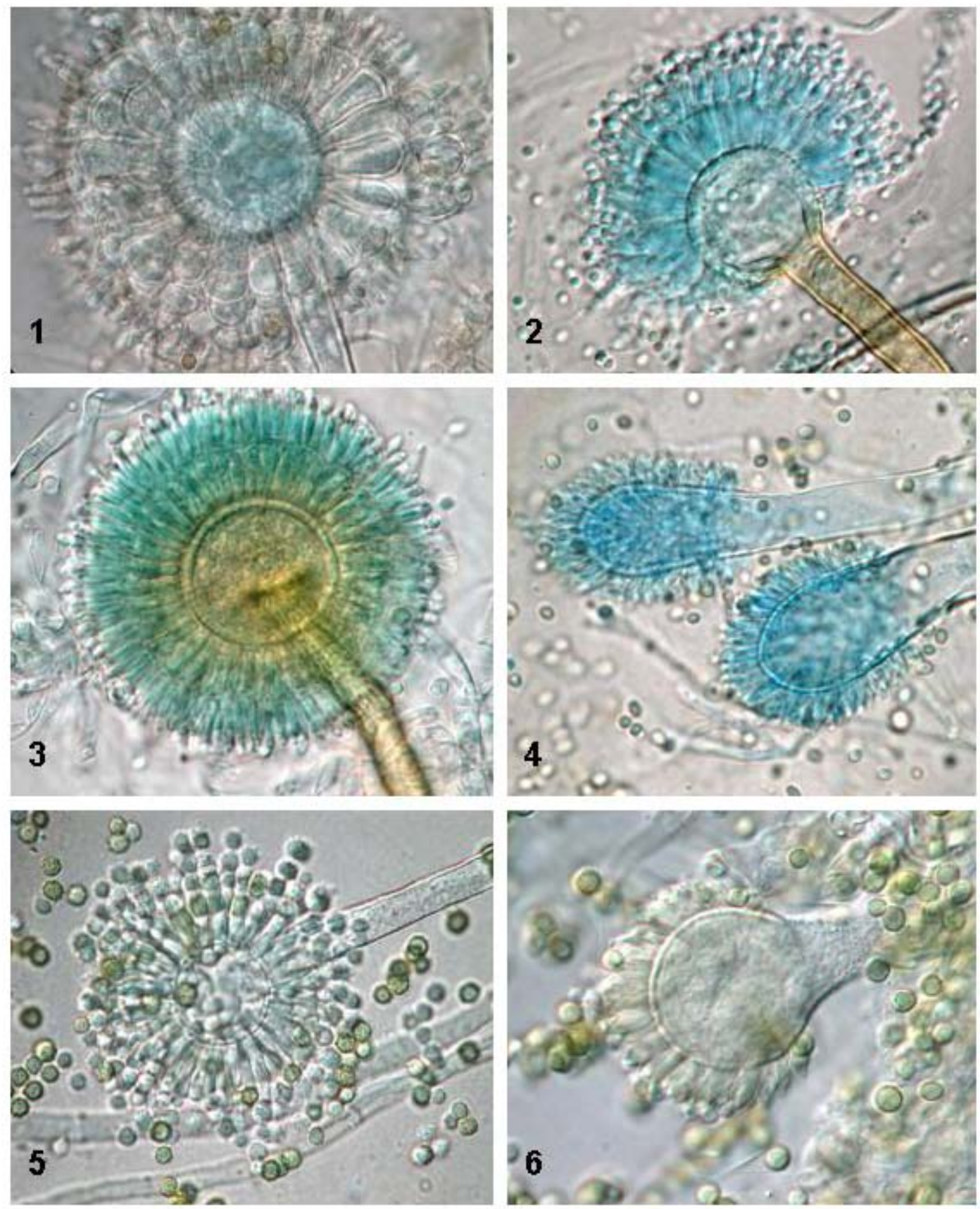

Figura 6. 1.- Aspergillus ellipticus. 2-. A. ochraceus. 3.- A. ostianus. 4.- A.clavatus. 5.- A. parasiticus. 6.- A. flavus. 

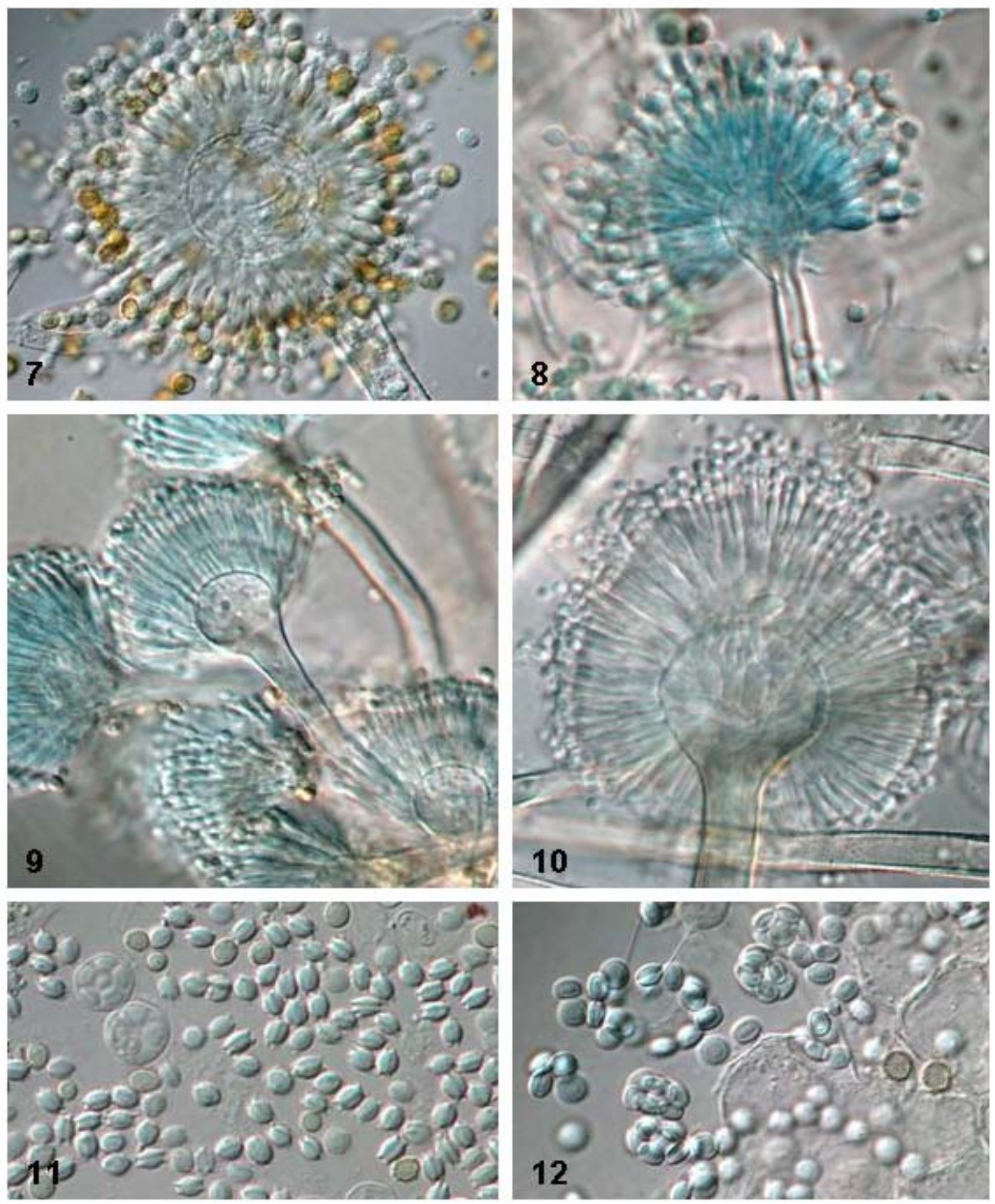

Figura 7. 7.- Aspergillus tamarii. 8-. A. versicolor. 9.- A. terreus. 10.- A. sclerotiorum. 11.- Eurotium amstelodami. 12.- E. rubrum. 
almacenados que poseen bajo contenido de humedad y su alto aislamiento no es sorpresivo en este substrato (Fernandez, 1986; Weidenbörner, 1997).

La incubación de A.flavus y A.parasiticus en agar coco y su posterior exposición bajo luz UV, ha sido una rápida y efectiva prueba en la detección de cepas aflatoxicogénicas (Lin \& Dianese, 1987). Davis et al. (1987), confirmaron por análisis químico la presencia de aflatoxinas en las cepas que producen halo azul fluorescente en este medio de cultivo. Las que producen halo intenso son potentes productoras de aflatoxinas, mientras las con halo tenue, son débiles productoras.

Aunque no contabilizamos la micota asociada al maíz debe destacarse la alta presencia de Fusarium verticillioide, otro gran colonizador de este cereal y cuyo conocido potencial toxicogénico no debe despreciarse (Ramírez et al., 1996; Dalcero et al., 1997: Chulze et al., 1998).

La presencia de cepas de A.flavus toxicogénicas, entre otras del género con similares capacidades (no analizadas), constituye una situación de alerta que debe considerarse con anterioridad al transporte, almacenaje, distribución y destino de estos granos en el país.

\section{CONCLUSIONES}

Los 2 medios de cultivo empleados en metodología permitieron detectar una alta presencia de especies del género Aspergillus en maíz y soja (18 taxas y 1669 colonias). Diecisiete especies se detectaron en maíz y 15 en soja. El medio AMS, permitió los mayores aislamientos.

Los 3 principales taxa en ambos granos (66\%) fueron: A.flavus, Eurotium amstelodami y E.rubrum y el subgénero Circumdati reunió con varios integrantes de sus secciones, prácticamente un $70 \%$ de todas las cepas del género. De las especies de la sección Flavi, sólo se aislaron A.flavus, A.parasiticus y A.tamarii.

En maíz se contabilizó un mayor número de cepas, siendo A. flavus dominante en todos los meses de estudio, con niveles cercanos al $50 \%$, mientras en soja, tuvo porcentajes cercanos al $30 \%$, pero no fue dominante en todos los meses, por la presencia de $\boldsymbol{E}$.

\section{amstelodami y E. rubrum.}

La distribución mensual de las especies de Aspergillus, tuvo valores más altos en maíz en julio, mientras que en soja fue en noviembre.

De los estudios morfológicos en A.flavus, se destaca que, los aspectos de las cabezas en AM fueron mayoritariamente radiadas laxas a columnares, prácticamente el 50 \% de las cepas fueron biseriadas, sus conidios a los 7 y 14 días no presentaron mayores variaciones en sus diámetros, pero levemente en sus rugosidades y la mayoría de las cepas formaron esclerocios (tipo L).

En las cepas de A.flavus analizadas, la presencia de aflatoxinas en agar coco fue de un $44 \%$, siendo noviembre el mes con mayor cantidad de cepas productoras. Las 2 cepas de A.parasiticus fueron negativas. Deben considerarse los taxa de otras secciones de Aspergillus como fuentes potenciales de diversas micotoxinas en estos granos, así como la alta presencia de Fusarium verticillioide en maíz, no sólo por su importancia en la dieta animal, sino por sus posibles repercusiones en salud pública.

La sola morfología no permitió determinar la presencia de diferentes grupos de compatibilidad vegetativa en los aislamientos de $\boldsymbol{A}$. flavus, pero al parecer la gran mayoría pueden ser representativos de clones genéticos muy semejantes, quizás provenientes y dispersos en una misma área geográfica de cultivos.

Si bien es cierto que nuestros resultados cualitativos reflejan un patrón general de distribución geográfica y temporal de las poblaciones de Aspergillus en las zonas de siembra de maíz y soja, los resultados cuantitativos deben valorarse con cautela, debido al transporte, manipulación de muestras y submuestras y los cambios en el tiempo en el microambiente de sus contenedores plásticos, una situación que puede haber alterado la distribución de sus propágulos.

\section{REFERENCIAS}

Al-Musallam, A. (1980). Revision of the Black Aspergillus Species. Drukkerij Elinkwink Bv., Utrecht.

Bolsa de cereales (1999).Número Estadístico 1999/2000. Buenos Aires. Argentina Cereal Office. Government Printing Office.

Barros, G.; Torres, A.; Palacio G. \& Chulze, S. (2003) Aspergillus sepecies from section Flavi isolated from soil at planting and harvest time in peanut-growing regions of Argentina. Journal of the Science of Food and Agriculture. 83: 1303-1307

Bayman, P.; \& Cotty, P. (1993). Genetic diversity in Aspergillus flavus: association with aflatoxin production and morphology. Can. J. Bot. 71:23-31

Christensen, M. \& Tuthill, D. E. (1985). Aspergillus: an overview. In: Samson RA, Pitt JI, (eds.) Advances in Penicillium and Aspergillus systematics. New York: Plenum Press. pp. 195209

Chulze, S.; Bertinetti, C.; Dalcero, A., et al. (1989). Incidence of aflatoxin, zearalenone and deoxynivalenol on corn in Argentina. Mycotoxin Research 5:9-12 
Chulze, S.; Ramirez, M.; Pascale, M. \& Visconti, A. (1998). Fumonisin production by, and mating populations of, Fusarium section Liseola isolates from maize in Argentina. Mycol. Res. 102:141-144

Cotty, P. J. (1989). Virulence and cultural characteristics of two Aspergillus flavus strains pathogenic on cotton. Phytopathology, 79:808-814

Cotty, P. J. (1991). Effect of harvest date on aflatoxin contamination of cottonseed. Plant Dis. 75:312-314

Cotty, P.J.; Bayman, P.; Egel, D.S. \& Elias, K.S. (1994) Agriculture, Aflatoxins and Aspergillus.In:Powell, K.A.; Renwick, A. \& Peberdy, J.F. (eds.) The Genus Aspergillus:from taxonomy and genetics to industrial applications. Plenum Press, N.Y. pp.1-27

Cotty, P. J., \& Cardwell, K. F. (1999). Divergence of West African and North American Communities of Aspergillus section Flavi. Appl. Environ. Microbiol. 65:2264-2266

Dalcero, A.; Magnoli, C.; Chiacchiera, S.; Palcios G.; Reynoso, M. (1997). Mycoflora and incidence of aflatoxin B1, zearalenone and deoxynivalenol in poultry feeds in Agentina. Mycopathología 137:179-84

Davis, N. D.; Iyer, S. K. \& Diener, U. L. (1987). Improved Method of Screening for Aflatoxin with a Coconut Agar Medium. Applied and Environmental Microbiology 53:1593-1595

Devegowda, G.; Radu, M.; Naza, R. A.; Swamy, H. (1998). Micotoxin Picture Worldwide: Novel Solutions for thei Counteraction en Proceedings of Alltech's $14^{\text {th }}$ Annual Symposium. Biotechnology in the Feed Industry. Passport of the Year 2000. Nortingham University Press, U. K. pp. 241 255

Doster, M. A. \& Michailides, T. J. (1994a). Development of Aspergillus molds in litter from pistachio trees. Pl. Dis. 78 393-397

Doster, M. A. \& Michailides, T. J. (1994b). Aspergillus molds and aflotoxins in pistachio nuts in California. Phytopathology 84:583-590

Egel, D. S.; Cotty, P. J. \& Elias, K. S. (1994). Relationships among isolates of Aspergillus sect. Flavi that Vary in Aflatoxin Production. Phytopathology 84:906-912

EHSO (Enviroment, Health and Safety Online) «Aflatoxins in Your Food-and their Effect on Your Health». U.S. FDA (Food and Drug Administration) REGULATIONS. En internet: http:/ /www.ehso.com/ehshome/aflatoxin.php (Consultado en 1-0504)

Etcheverry, M.; Nesci, A.; Barros, G.; Torres, A.; Chulze, S. (1999). Ocurrence of Aspergillus section Flavi and aflatoxin B1 in corn genotypes and corn meal in Argentina. Mycopathologia 147:37-41

Farnochi, C.; Torres, A.; Rizzo I. \& Varsavsky, E. (1988) Incidencia de aflatoxinas, zearalenona y deoxinivalenol (DON) en maíz. V Congreso Argentino de Microbiología. Noviembre. Mar del Plata, Argentina.

Fernández Pinto, V. (1986). Estudio de Factores que condicionan la producción de aflatoxinas en soja: influencia de la variedad, actividad acuosa, temperatura tiempo de incubación. Tesis, Facultad de Ciencias Exactas y Naturales, Universidad de Buenos Aires.

Geiser, D. M.; Pitt, J. I.\& Taylor, J. W. (1998). Cryptic speciation and recombination in the aflatoxin-producing fungus SApergillus flavus. Proc. Natl. Acad. Sci. USA. 95:388-393
González, H. H. L.; Resnik, S. L.\& Vaamonde, G. (1988). Influence of temperature on growth rate and lag phase of fungi isolated from Argentina corn. Int.J.Food Micobiol. 6:179-183

Gonzalez, H.H.L.; Martinez, E.J. \& Resnik, S.L. (1997). Fungi associated with sorghum grain from Argentina. Micopathologia 139:35-41

Hesseltine, C. W.; Shotwell, O. L.; Smith M.; Ellis J. J.; Vandegraft, E.; Shannon, G. (1970). Production of various aflatoxins by strain s of the 6 series. In: M. Herzberg (ed.), Toxin microorganisms: mycotoxins, botulism. U.S. Department of the Interior, Washington, D.C. pp.202-210

Hocking, A. D. (1991). Xerophilic fungi in intermediae and low moisture foods. Handbook of Applied Mycology. Vol.3: Food and Feeds 3:69-97

Horn, B.; Greene, R. L.; Sobolev, V. S.; Dorner, J. W.; Powell, J. H.; Layton, R. C. (1996). Association of morphology and mycotoxin production with vegetative compatibility groups in Aspegillus flavus, A. parasiticus, and A. tamarii. Mycologia 88: 574-587

Horn, B.W. \& Dorner, J.W. (1998). Soil populations of Aspergillus species from section Flavi along a transect through peanut-growing regions of the United States. Mycologia 90: 767-776

Klich, M. A. \& Pitt, J. I. (1988). A Laboratory guide to common Aspergillus species and their teleomorphs. CSIRO Division of Food Processing, North Ryde. Australia.

Klich, M. A. (2002a). Identification of Common Aspergillus species. United States Department of Agriculture Agricultural Research Service, Southern Regional Research Center New Orleans, Louisiana USA.

Klich, M. A. (2002b). Biogeography of Aspergillus species in soil and litter. Mycologia 94:21-27

Kozakiewicz, Z. (1989).Aspergillus species on stored products Micological Papers. $\mathrm{N}^{\circ}$ 161. CAB. International

Kurtzman, C. P.; Horn, B.W. \& Hesseltine, C.W. (1987). Aspergillus nomius, a new aflatoxin-producing species related to Aspergillus flavus and Aspergillus tamarii. Antonie Van Leeuwenhoek 53:147-158

Lin, M. T. \& Dianese, J. C. (1976). A coconut-agar medium for rapid detection of aflatoxin production by Aspergillus spp. Phytopathology 66:1466-1469

Magnoli, C.; Dalcero, AM.; Chiacchiera, S.M.; Miazzo, R.; Saenz, M.A. (1998). Enumeration and identification of Aspergillus group and Penicillium species in poultry feeds from Argentina. Mycopathologia 142:27-32

McAlpin, C. E.; Wicklow, D. T. \& Horn, B. W. (2002). DNA Fingerprinting Analysis of Vegetative Compatibility Groups in Aspergillus flavus fron a Peanut Field in Georgia. Plant Dis. 86: 254-258

Moss, M.O. (1991). Mycology of cereal grain and cereal

products. Developments in Food Science 28:23-51

Nepote, M.; Saubois, A. \& Basilico, J. C. (1988). Incidencia de micotoxinas en maíz proveniente de un molino harinero de la ciudad de Santa Fe. V Congreso Argentino de Microbiología. Noviembre Mar del Plata, Argentina.

Nepote, M.C; Saubois, A.; Beccaria, A. \& Basilico, J. (1994). Grado de contaminación por aflatoxinas y zearalenona 
en maíz y subproductos procesados en un molino harinero de la ciudad de Santa Fe (Argentina). Rev. Ibreoam. Micol. 11:37-39

Nepote, M.C.; Piontelli, E. \& Saubois. A. (1995). Evaluación micológica de granos de sorgo de la provincia de Santa Fe. Proceedings of the VII Congreso Argentino de Microbiología, Buenos Aires, Argentina; p. 10.

Nepote, M.C.; Piontelli, E.\& Saubois, A. (1997). Ocurrence of Aspergillus flavus strains and aflatoxins in corn fron Santa Fe, Argentina. Arch. Latinoam. Nutr. 47:262-4

Nesci, A., \& Etcheverry, M. (2002). Aspergillus section Flavi populations from field maize in Argentina. Letters in Applied Microbiology 34:343-348

Niyo, K. A. (1990). Mycotoxins: economic and health risks Council on Agricultural Science and Technology, Ames, Iowa. No. 116.

Osweiler, G. D. (1992). Mycotoxins en Diseases of Swine. $7^{\text {th }}$ Edition, Wolfe Publishing, London. pp. 735-743.

Picco, M.; Nesci, A.; Barros, G.; Cavaglieri, L.; Etecheverry, M. (1999). Aflatoxin B1 and fumosin B1 in mixed cultures of Aspergillus flavus and Fusarium proliferatum on maize. Nat Toxins. 7:331-6

Picco, A.M \& Piontelli, E.(2005).VII. Muffe contaminanti di alimenti e derrate alimentari. En: Rondanelli, E,G.; Fabbi,M.\& Marone,P. (Eds.)Trattato sulle infezioni e tossinfezioni alimentari, Selecta Medica, Pavia. pp. 845-897

Pildain, M. B.; Vaamonde, G. \& Cabral, D. (2004). Analysis of population structure of Aspergillus flavus from peanut based on vegetative compatibility, geographic origin, mycotoxin and sclerotia production. Int. J. Food Microbiol. 93:31-40

Ramírez, M.; Pascale, M.; Chulze, S.; Reynoso, M.; March, G.; Visconti, A. (1996). Natural ocurrence of fumonisins and their correlation to Fusarium contamination in commercial corn hybrids growth in Argentina. Mycopathologia 135:29-34

Raper, K. B. \& Fennell D. I. (1965). The Genus Aspergillus, Williams \& Wilkins Company, Baltimore.

Reddy, B. N. (1987). Aflatoxin producing potential of Aspergillus flavus isolates from sorghum. Indian Phytopathology 40 550-551

Resnik, S. L. (1988a). Almacenamiento de granos. Prevención de la contaminación por hongos y micotoxinas. Seminario Latinoamericano y del Caribe sobre Micotoxinas, 14 al 18 de noviembre 1988, Buenos Aires, Argentina.

Resnik, S. L. (1988b). Situación del problema de las micotoxinas en la República Argentina. Seminario Latinoamericano y del Caribe sobre Micotoxinas. Buenos Aires, Argentina. 14-18 de noviembre 1988

Resnick, S. L. (1989). Factores que inciden en la aparición de micotoxinas desde la producción primaria hasta el almacenamiento. Jornada Nacional sobre Micotoxinas y Micotoxicosis». Programa Postcosecha. Estación experimental La Platina. Serie La Platina $n^{\circ} 13$, Santiago Chile.

Resnick, S.L.; Neira, S.; Pacin, A.; Martínez, E.; Apro, N.; Latreite, S. (1996). A survey of the natural ocurrence of aflatoxin and zearalenone in Argentina field maize: 1983-84. Food Aditives and Contaminants. 13:115-120

Resnick, S. L. (1997). Micotoxinas. Rev. Arg. Prod. Anim., Bs. As. 17:221 225

Saito, M.; Tsuruta, O.; Siriacha, P.; Kawasugi, S.; Manabe, M.; Buangsuwon, D. (1986). Distribution and aflatoxin productivity of the atypical strain of Aspergillus flavus isolated from soils in Thailand. Proc. Jpn. Assoc. Mycotoxicol. 24: 4146

Samson, R. A.; Hoekstra, E.S.; Frisvad, J. C. \& Filtenborg, O. (2000). Introduction to Food-Borne Fungi. $6^{\text {th }}$ edn. CBS, Utrecht.

Van Egmond, H.P. (1989). Introducction. In: Van Egmond, (ed.) Micotoxin in dairy products. Elsevier, London, pp. 1-9

Varsavsky, E.; Vaamonde, G. \& Resnik, S. L. (1985). Micotoxinas: Panorama actual en la República Argentina. SECyT.

Weidenbörner, M. (1997). The mycoflora of soybean seeds in relation to the used plating medium DG 18 or MSA. Nahrung 41(S): 239-240

Weidenbörner, M.; Berleth, M.; Krämer, J.; Kunz, B. (1996). Investigations about the mycoflora of selected samples of the german cereal crop 1994. Adv. Food Sci. (CMTL) 18:103-106

Wicklow, D. T.; Horn, B. W.; Burg, W. R. \& Cole, R. J. (1984). Sclerotium dispersal of Aspergillus flavus and Eupenicillium ochrosalmoneum from maize during harvest. Trans. Br. Mycol. Soc. 83: 299-303

Wicklow, D. T.; Dowd, P. F.; Tepaske, M. R., \& Gloer, J. B. (1988). Sclerotial metabolites of Aspergillus flavus toxic to a detritivorous maize insect (Carpophilus hemipterus, Nitidulidae). Trans. Br. Mycol. Soc. 91: 433-438

Wicklow, D.T. (1991). Epidemiology of Aspergillus flavus in corn. In Aflatoxin in Corn: New perspectives (O. L. Shotwell \& C. R. Hurburgh Jr. (Eds.)) pp. 315-328. Iowa Agriculture and Home Economics Experiments Station Research Bulletin 599: Ames, Iowa.

Wicklow, D.T. (1995). The Mycology of Stored Grain: An Ecology Perspective. Stored-Grain Ecosystems 7:197-249

Woloshuk, C.P.; Cavaletto, J.R. \& Cleveland, T.E. (1997). Inducers of Aflatoxin Biosynthesis from Colonized Maize Kernels Are Generated by an Amylase Activity from Aspergillus flavus. Biochemistry and Cell Biology 87:164-169

Zumo, N. \& Scott, G.E. (1990). Relative aggresiveness of Aspergillus flavus and $A$. parasiticus in maize in Mississipi. Plant Disease 74:978-981 